\title{
Pd(II) Complexes with Nitrogen-oxygen Donor Ligands: Synthesis, Characterization and Catalytic Activity for Suzuki-Miyaura Cross-coupling Reaction
}

\author{
M. T. AMALINA ${ }^{1}$, B. HADARIAH ${ }^{1 *}$, K. KARIMAH $^{1}$ \\ AND W. I. W. NAZIHAH ${ }^{1}$
}

\begin{abstract}
Inexpensive bidentate Schiff base ligands (O1, O3) and their Pd(II) complexes (OPd1, OPd3) were successfully synthesized and characterized using $\mathrm{CHN}$ elemental analysis, FTIR, ${ }^{1} \mathrm{H}$ and ${ }^{13} \mathrm{C} \mathrm{NMR}$, melting point determination, molar conductivity and magnetic moment. It revealed that these Schiff bases behaved as bidentate ligands in their complexes. The spectral data indicated that the ligands co-ordinated through the phenolic oxygen and the azomethine nitrogen atoms. Magnetic moment data suggested the existence of square planar Pd(II) complexes, while non-electrolytic behaviour indicated the absence of counter ions in chloroform. The Pd(II) complexes showed good catalytic activities for Suzuki-Miyaura cross-coupling reaction between iodobenzene with phenylboronic acid at $1.0 \mathrm{mmol} \%$ catalyst loading.
\end{abstract}

Key words: Bidentate Schiff base; nitrogen-oxygen donor ligands; Pd(II); Suzuki-Miyaura crosscoupling reaction; synthesis; physicochemical properties; catalytic activity; characterization

Schiff base ligands are considered 'privileged ligands' and are attractive because they are easily prepared by the condensation between aldehyde/ketone and imines both of which are relatively cheap and easily available. Stereogenic centres or other elements of chirality such as planes and axes can be introduced in the synthetic design (Cozzi 2004) as well as benzene rings containing electron donating or withdrawing substituents. The mono-, di- , tri- and multi-dentate chelating Schiff base ligands can be designed according to the binding environments of metal ions. The metal complexes of chiral Schiff base ligands showed stereoselectivity in organic transformation, hence the synthesis of chiral complexes become an important area of current research in co-ordination chemistry (Gupta \& Sutar 2008).
Schiff base ligands are able to co-ordinate many different metals (Osman 2006; Sallam 2006) and to stabilize them in various oxidation states. The Schiff base complexes have been used in catalytic reactions (Dhara et al. 2010; Tamizh \& Karvembu 2012) and as models for biological systems (Singh et al. 2012; Mohamed et al. 2010). Many Schiff base complexes show excellent catalytic activity in various reactions at high temperature $\left(>100^{\circ} \mathrm{C}\right)$ and in the presence of moisture (Gupta \& Sutar 2008).

The Suzuki-Miyaura cross-coupling reaction is a powerful method for the synthesis of biaryl bonds. The importance of biaryl units as molecular components in pharmaceuticals, herbicides and natural products, as well as in engineering materials such as conducting polymers, molecular wires and liquid crystals,

\footnotetext{
${ }^{1}$ Faculty of Applied Sciences, Universiti Teknologi MARA, 40450 Shah Alam, Selangor, Malaysia

* Corresponding author (e-mail: hadariah@salam.uitm.edu.my)
} 
has attracted enormous interest (Paul \& Clark 2003). Numerous variants (Gillis \& Burke 2009), optimizations and applications (McGlaken \& Fairlamb 2009) have been disclosed in the literature. The robust nature of this reaction has led to its widespread use in the pharmaceutical industry (Torborg \& Beller 2009). The relative thermal stability, insensitivity to air or moisture, and low toxicity (Miyaura \& Suzuki 1995) of boronic acid constitute a highly valuable practical advantage for both academic and industrial applications.

As a part of our interest in designing new, inexpensive ligands and studying their co-ordination behaviour and catalytic application, we report herein the synthesis and characterization of a new type of ligands and their Pd(II) complexes as catalysts in SuzukiMiyaura cross-coupling reaction.

\section{MATERIALS AND METHODS}

\section{Experimental Sections}

Materials. All reagents and chemicals used in this investigation were laboratory pure grade available from Acros, Merck and SigmaAldrich. The solvents for the spectral study were spectroscopic grade and used without further purification.

Techniques. Microanalyses for carbon, hydrogen and nitrogen were determined using a Thermo Finnigan Flash Elemental Analyzer 2000. The IR spectra were obtained on a Perkin Elmer 1750X FTIR spectrophotometer $\left(4000 \mathrm{~cm}^{-1}-400 \mathrm{~cm}^{-1}\right)$ with samples prepared as $\mathrm{KBr}$ pellets. Melting points of the products were determined using Buchii-B454 and are uncorrected. Proton $\left({ }^{1} \mathrm{H}\right)$ and carbon $\left({ }^{13} \mathrm{C}\right) \mathrm{NMR}$ $(300 \mathrm{MHz})$ spectra were recorded on a Bruker Varian spectrometer in $\mathrm{CDCl}_{3}$ and reported in p.p.m. $(\delta)$ from the internal standard TMS. The magnetic susceptibilities were determined on Sherwood Auto Magnetic Susceptibility Balance at room temperature $\left(25^{\circ} \mathrm{C}\right)$ using $\mathrm{Hg}\left[\mathrm{Co}(\mathrm{SCN})_{4}\right]$ as a calibrant; the diamagnetic

corrections were calculated from Guoy method. Molar conductance measurements of freshly prepared Schiff base ligands and their transition metal complexes solutions were determined in chloroform $\left(\sim 10^{-3} \mathrm{M}\right)$ at room temperature using a Mettler Toledo Inlab 730 conductivity meter. The formation of products from catalytic testing was monitored using Gas Chromatography (GC) technique (Bhunia et al . 2010). Yields were calculated for a specific set of parameters at a specific time according to the product ratios.

Synthesis of Schiff base ligands.

$\overbrace{\mathrm{OCH}_{3}}^{\mathrm{OH}}$

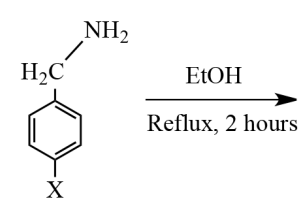

$\mathrm{X}: \mathrm{H}, \mathrm{OCH}_{3}$

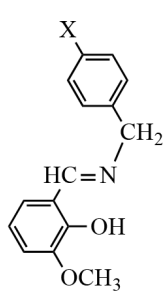

Figure 1. General reaction for the synthesis of Ovan-series ligands.

Synthesis of (E)-2-[(benzylimino)methyl]-6methoxyphenol [O1]

To $o$-vanillin $(50 \mathrm{mmol}, 7.6091 \mathrm{~g}$ ) was dissolved in ethanol $(25 \mathrm{ml})$, an ethanolic solution of benzylamine ( $50 \mathrm{mmol}, 5.3869 \mathrm{~g}$ ) was added and the mixture was stirred for overnight. The ethanol was allowed to evaporate slowly at room temperature. Orange-coloured solid product was evident after a week. The solid residue was filtered, washed with ice-cold ethanol and air-dried at room temperature. The yield was $36.8 \%$.

Synthesis of (E)-2-methoxy-6-[(4-methoxybenzylimino)methyl]phenol [O3]

To $o$-vanillin $(2 \mathrm{mmol}, 0.3075 \mathrm{~g}$ ) was dissolved in ethanol $(5 \mathrm{ml})$, an ethanolic solution of 4-methoxybenzylamine ( $2 \mathrm{mmol}, 0.2744 \mathrm{~g}$ ) was added dropwise and the mixture was heated under reflux for $2 \mathrm{~h}$. Upon cooling, there was 
no formation of solid materials. Ethanol was removed using rotary evaporator. The ligand was used in complexation with $\mathrm{Pd}(\mathrm{II})$ metal salt.

\section{Synthesis of Pd(II) complexes.}

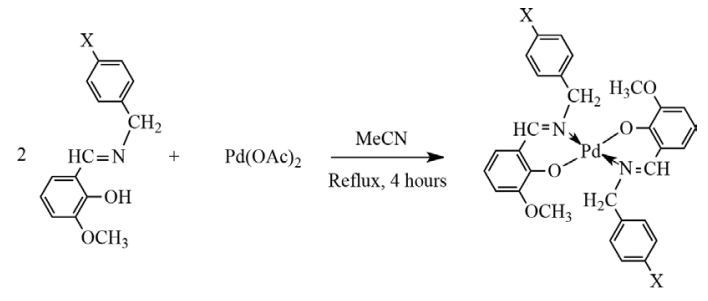

$\mathrm{X}: \mathrm{H}, \mathrm{OCH}_{3}$

Figure 2. General reaction for the synthesis of Pd-Ovan-series complexes.

Synthesis of Bis(2-((E)-(benzylimino)methyl)6-methoxyphenoxy)palladium(II) [OPd1]

The ligand, O1, (5 mmol, $1.2064 \mathrm{~g}$ ) was dissolved in acetonitrile $(10 \mathrm{ml})$ in a roundbottomed flask. Palladium(II) acetate ( $2.5 \mathrm{mmol}, 0.5612 \mathrm{~g}$ ) was dissolved separately in acetonitrile $(10 \mathrm{ml})$ and added into the flask containing the ligand solution. The mixture was stirred and refluxed for $4 \mathrm{~h}$ upon which brown solids were formed. It was isolated by gravity filtration, washed with ice-cold acetonitrile and air dried at room temperature. The yield was $90.6 \%$.

Synthesis of Bis(2-methoxy-6-((E)-(4methoxybenzylimino)methyl)phenolato) palladium(II) [OPd3]

The ligand, O3, (2 mmol, $0.5426 \mathrm{~g}$ ) was dissolved in acetonitrile $(5 \mathrm{ml})$ in a roundbottomed flask. Palladium(II) acetate (1 mmol, $0.2246 \mathrm{~g})$ was dissolved separately in acetonitrile $(5 \mathrm{ml})$ and added into the flask containing the ligand solution. The mixture was stirred and refluxed for $4 \mathrm{~h}$ upon which a brown solid was formed. It was isolated by gravity filtration, washed with ice-cold acetonitrile and air dried at room temperature. The yield secured was $80.8 \%$.
General reaction of Suzuki-Miyaura crosscoupling reaction. The palladium(II) Schiff base complexes were tested as homogeneous catalysts in a series of Suzuki-Miyaura crosscoupling reaction, between iodobenzene and phenylboronic acid to produce biphenyl. The general procedure (Figure 1) is as follows: Iodobenzene (1 mmol), phenylboronic acid ( $2 \mathrm{mmol})$, triethylamine, $\mathrm{Et}_{3} \mathrm{~N}(2.4 \mathrm{mmol})$, palladium(II) Schiff base $(0.01 \mathrm{mmol})$ and solvent DMA (7 ml) were mixed in Radley's 12-placed reaction carousel and refluxed whilst being purged with nitrogen. The reaction was monitored every $6 \mathrm{~h}$ and sampling was done at $6 \mathrm{~h}, 12 \mathrm{~h}$ and $24 \mathrm{~h}$.

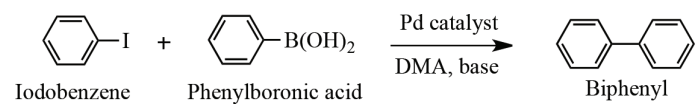

Figure 3. Catalytic reaction of iodobenzene with phenylboronic acid.

\section{RESULTS AND DISCUSSION}

\section{Physicochemical Properties of the Synthesized Compounds}

All of these bidentate Schiff base ligands and their Pd(II) complexes were intensely coloured, air and moisture free. The ligands and their metal complexes were very stable solids at room temperature, without undergoing decomposition. Yields of the complexes were higher than those of the ligands. The ligands had very high solubility in almost all polar solvents attributable to their polar nature. The complexes however, had very low solubility in polar organic solvents such as $\mathrm{Et}_{3} \mathrm{OH}$, $\mathrm{MeOH}, \mathrm{DMSO}, \mathrm{CH}_{2} \mathrm{Cl}_{2}$, etc. but soluble in relatively less polar $\mathrm{CHCl}_{3}$. These synthesized ligands contained both polar and non-polar groups such as $-\mathrm{OH},-\mathrm{OCH}_{3},-\mathrm{CH}_{3}$ etc. The $\mathrm{C}, \mathrm{H}$ and $\mathrm{N}$ percentages were theoretically calculated and the measured values were in accordance to the suggested formula. The physical and analytical data of the Schiff base ligands and their complexes are shown in Table 1. 
Table 1. Physical and analytical data for ovan-series ligands and their complexes.

\begin{tabular}{c|cccccc}
\hline $\begin{array}{c}\text { Ligand/ } \\
\text { Complex }\end{array}$ & $\begin{array}{c}\text { Empirical } \\
\text { formula }\end{array}$ & Colour & $\begin{array}{c}\text { Melting point } \\
\left({ }^{\circ} \mathrm{C}\right)\end{array}$ & \multicolumn{3}{c}{ Elemental Analysis (\%) (Found) } \\
\hline $\mathrm{O} 1$ & $\mathrm{C}_{15} \mathrm{H}_{15} \mathrm{NO}_{2}$ & Yellow & $62-65$ & $74.67 \mathbf{( 7 4 . 7 7 )}$ & $6.27(\mathbf{6 . 3 1})$ & $5.81(\mathbf{5 . 9 1})$ \\
$\mathrm{OPd} 1$ & $\mathrm{C}_{30} \mathrm{H}_{28} \mathrm{~N}_{2} \mathrm{O}_{4} \mathrm{Pd}$ & Brown & $259-261$ & $61.39(\mathbf{6 1 . 4 7 )}$ & $4.81(\mathbf{4 . 7 9 )}$ & $4.77 \mathbf{( 4 . 7 4 )}$ \\
$\mathrm{O} 3$ & $\mathrm{C}_{16} \mathrm{H}_{17} \mathrm{NO}_{3}$ & Yellow & - & $70.83 \mathbf{( 7 1 . 0 8 )}$ & $6.32(\mathbf{6 . 3 2})$ & $5.23 \mathbf{( 5 . 2 3 )}$ \\
$\mathrm{OPd} 3$ & $\mathrm{C}_{32} \mathrm{H}_{32} \mathrm{~N}_{2} \mathrm{O}_{6} \mathrm{Pd}$ & Brown & $204-205$ & $59.40(\mathbf{5 9 . 1 2})$ & $4.98 \mathbf{( 4 . 9 9 )}$ & $4.33 \mathbf{( 4 . 3 5 )}$ \\
\hline
\end{tabular}

\section{IR Spectral Studies}

In general, all infrared spectra presented the same general characteristics. The appearance of the $\mathrm{C}=\mathrm{N}$ (azomethine) peaks in the range $1620-1634 \mathrm{~cm}^{-1}$ could be clearly seen in the spectra, indicating the formation of the Schiff bases. The broad band at $2300 \mathrm{~cm}^{-1}-3300 \mathrm{~cm}^{-1}$ could be attributed to the intramolecular hydrogen-bonded O-H group (Zolezzi et al. 1999). This band was absent in the spectra of complexes due to deprotonation of the phenolic moiety upon complexation. The Pd(II) ion was co-ordinated through the nitrogen and oxygen atoms of the hydroxyl group. The azomethine $\mathrm{C}=\mathrm{N}$ bands were seen to be shifted to lower frequencies, $1612 \mathrm{~cm}^{-1}-1623 \mathrm{~cm}^{-1}$ in all $\mathrm{Pd}(\mathrm{II})$ complexes due to the withdrawal of electron density from the nitrogen atom owing to co-ordination (Zolezzi et al. 1999). A similar effect was observed in the stretching vibration of the Schiff base phenolic C-O and methoxy groups, with respect to the same group in the complexes where it was shifted to a lower frequency, strongly indicating oxygen co-ordination to the metal centre. The appearance of new bands at $462 \mathrm{~cm}^{-1}-544 \mathrm{~cm}^{-1}$ and $581 \mathrm{~cm}^{-1}-660 \mathrm{~cm}^{-1}$, that ascribed $\mathrm{Pd}-\mathrm{O}$ and $\mathrm{Pd}-\mathrm{N}$ vibrations, support the evidence of the participation of the nitrogen atom of the azomethine group and oxygen atom of the of $\mathrm{OH}$ group of the ligand in the complexation with metal ions (Ouf et al. 2010; Mustafa et al. 2009). The significant bands of ligands and their Pd(II) complexes and their spectra are summarized in Table 2 and Figure 4.

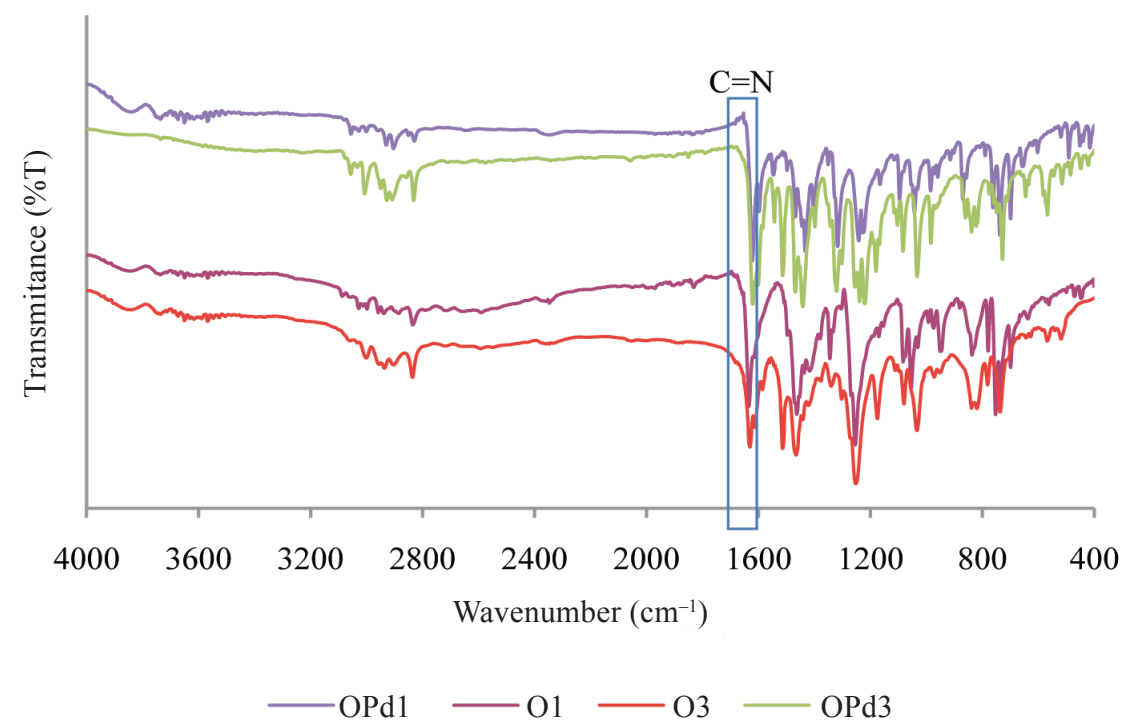

Figure 4. FTIR Spectra of O1, O3, OPd1 and OPd3. 
Table 2. Infrared data for ligands and their Pd(II) complexes.

\begin{tabular}{c|cccccc}
\hline Ligand/ & \multicolumn{5}{|c}{ Frequency $\left(\mathrm{cm}^{-1}\right)$} \\
Complex & $\mathbf{v}(\mathrm{C}=\mathrm{N})$ & $\mathbf{v}(\mathrm{C}-\mathrm{N})$ & $\mathbf{v}(\mathrm{C}-\mathrm{O})$ & $\mathbf{v}\left(\mathrm{OCH}_{3}\right)$ & $\mathbf{v}(\mathrm{C}-\mathrm{OH})$ & $\mathbf{v}(\mathrm{M}-\mathrm{O}, \mathrm{M}-\mathrm{N})$ \\
\hline O1 & $1634(s)$ & $1344(w)$ & $1254(s)$ & $1054(w)$ & $2300-3300(b)$ & - \\
$\mathrm{OPd} 1$ & $1622(s)$ & $1316(s)$ & $1241(s)$ & $1095(w)$ & - & $657416(w)$ \\
O3 & $1630(w)$ & $1344(w)$ & $1251(s)$ & $1033(w)$ & $2500-3200(b)$ & - \\
OPd3 & $1620(s)$ & $1320(s)$ & $1239(s)$ & $1032(w)$ & - & $567515(w)$ \\
\hline
\end{tabular}

$(s)=$ Strong; $(b)=$ Broad $;(w)=$ Weak.

\section{${ }^{1} \mathrm{H}$ and ${ }^{13} \mathrm{C}$ NMR Studies}

In the ${ }^{1} \mathrm{H}$ NMR of the ligands (Table 3), the chemical shift for methylene appear at 4.74 p.p.m. -4.82 p.p.m. as singlets and slightly shifted to higher values of 5.04 p.p.m.5.12 p.p.m. in their respective $\mathrm{Pd}(\mathrm{II})$ complexes. The methoxy peaks for ligands appear at 3.88 p.p.m. -3.90 p.p.m. while in complexes, they appear at 3.75 p.p.m. -3.76 p.p.m., slightly shifted to lower values. Upon co-ordination, there is an upfield shift of peaks for azomethine protons from 8.38 p.p.m. -8.42 p.p.m. to 7.69 p.p.m.-7.72 p.p.m.. This upfield shift is attributed to the conformational change that occurs in the ligand upon chelation (Mahamo et al. 2012). The phenolic proton appears at 13.85 p.p.m. in $\mathrm{O} 1$ and disappeared upon complexation, indicating that the complexation was successfully achieved through deprotonation of the phenol. The $\mathrm{OH}$ peak in $\mathrm{O} 3$ that was expected to appear in the downfield region (10 p.p.m.-14 p.p.m.) (Saheb \& Sheikhshoaie 2011) of the spectra was not observed as the labile phenolic proton may have undergone a rapid exchange with the deuterium in the solvent.

The ${ }^{13} \mathrm{C}$ singlet signals for the imine carbons $(\mathrm{C}=\mathrm{N})$ in complexes are found in the region 162.3 p.p.m.-162.8 p.p.m. (Table 4). This is an upfield shift from 165.2 p.p.m.-165.6 p.p.m. observed for the free ligands, further affirming the co-ordination of the ligand through the imine group to the metal centre. There is

Table 3. Chemical shift of ${ }^{1} \mathrm{H}$ NMR for ligands and their Pd(II) complexes.

\begin{tabular}{ccccc}
\hline \multirow{2}{*}{ Assignments } & \multicolumn{5}{c}{ Chemical shifts (p.p.m.) } \\
& $\mathrm{O} 1$ & $\mathrm{OPd} 1$ & $\mathrm{O} 3$ & $\mathrm{OPd} 3$ \\
\hline $\mathrm{C}-\underline{\mathbf{C}} \mathrm{H}_{2}$ & $4.82(s)$ & $5.12(s)$ & $4.74(s)$ & $5.04(s)$ \\
$\mathrm{N}=\underline{\mathbf{C}} \mathrm{H}$ & $8.42(s)$ & $7.72(s)$ & $8.38(s)$ & $7.69(s)$ \\
$\underline{\mathbf{C}}^{3}-\mathrm{H}(\mathrm{Ar})$ & $6.84-6.89(d)$ & $6.76-6.81(d)$ & $6.92-6.93(d)$ & $6.78-6.79(d)$ \\
$\underline{\mathbf{C}}^{4}-\mathrm{H}(\mathrm{Ar})$ & $6.81-6.84(t)$ & $6.47-6.52(t)$ & $6.86-6.89(t)$ & $6.83-6.84(t)$ \\
$\underline{\mathbf{C}}^{5}-\mathrm{H}(\mathrm{Ar})$ & $6.89-6.91(d)$ & $7.26-7.29(d)$ & $7.21-7.24(d)$ & $7.36-7.39(d)$ \\
$\underline{\mathbf{C}}^{13}-\mathrm{H}(\mathrm{Ar})$ & $6.91-7.26(t)$ & $7.29(t)$ & - & - \\
$\underline{\mathbf{C}}^{11}, \underline{\mathbf{C}}^{15}-\mathrm{H}(\mathrm{Ar})$ & $7.32(d)$ & $7.44-7.46(d)$ & $6.76-6.79(d)$ & $6.47-6.52(d)$ \\
$\underline{\mathbf{C}}^{12}, \underline{\mathbf{C}}^{14}-\mathrm{H}(\mathrm{Ar})$ & $7.26-7.32(t)$ & $7.22-7.26(t)$ & $7.29-7.30(d)$ & $6.77-6.86(d)$ \\
$\mathrm{C}^{13}-\mathrm{O} \underline{\mathbf{C}} \mathrm{H}_{3}$ & - & - & $3.79(s)$ & $3.77(s)$ \\
$\mathrm{Ar}_{3}-\mathrm{O} \underline{\mathbf{C}} \mathrm{H}_{3}$ & $3.90(s)$ & $3.75(s)$ & $3.88(s)$ & $3.76(s)$ \\
$\underline{\mathbf{C}}^{1}-\mathrm{OH}$ & $13.85(b)$ & - & $\mathrm{N} . \mathrm{D}$. & - \\
\hline
\end{tabular}

$(s)=$ Singlet; $(d)=$ Doublet; $(t)=$ Triplet; $(b)=$ Broad; N.D. $=$ Not detected; Ar = Aromatic . 
Table 4. Chemical shift of ${ }^{13} \mathrm{C}$ NMR for ligands and their Pd(II) complexes.

\begin{tabular}{c|cccc}
\hline \multirow{2}{*}{ Assignments } & \multicolumn{4}{|c}{ Chemical shifts (p.p.m.) } \\
& $\mathrm{O} 1$ & OPd1 & O3 & OPd3 \\
\hline $\mathrm{C}-\underline{\mathbf{C}} H_{2}$ & $62.68(s)$ & $58.85(s)$ & $64.40(s)$ & $58.33(s)$ \\
$\mathrm{N}=\underline{\mathbf{C}} \mathrm{H}$ & $165.6(s)$ & $162.8(s)$ & $165.2(s)$ & $162.3(s)$ \\
$\underline{\mathbf{C}}-\mathrm{H}(\mathrm{Ar})$ & $113.9(s)$ & $114.0(s)$ & $114.0(s)$ & $113.8(s)$ \\
$\underline{\mathbf{C}}-\mathrm{H}(\mathrm{Ar})$ & $117.9(s)$ & $120.2(s)$ & $117.8(s)$ & $113.8(s)$ \\
$\underline{\mathbf{C}}^{5}-\mathrm{H}(\mathrm{Ar})$ & $122.9(s)$ & $125.4(s)$ & $122.9(s)$ & $125.4(s)$ \\
$\underline{\mathbf{C}}^{13}-\mathrm{H}(\mathrm{Ar})$ & $127.3(s)$ & $127.1(s)$ & $158.8(s)$ & $158.8(s)$ \\
$\underline{\mathbf{C}}^{11}, \underline{\mathbf{C}}^{15}-\mathrm{H}(\mathrm{Ar})$ & $127.5(s)$ & $127.1(s)$ & $129.9(s)$ & $129.8(s)$ \\
$\underline{\mathbf{C}}^{12}, \underline{\mathbf{C}}^{14}-\mathrm{H}(\mathrm{Ar})$ & $128.6(s)$ & $128.4(s)$ & $114.2(s)$ & $114.0(s)$ \\
$\mathrm{C}^{13}-\mathrm{O} \underline{\mathbf{C}} \mathrm{H}_{3}$ & - & - & $55.30(s)$ & $55.24(s)$ \\
$\mathrm{Ar}_{3}-\mathrm{O} \underline{\mathbf{C}} \mathrm{H}_{3}$ & $56.01(s)$ & $55.90(s)$ & $56.04(s)$ & $55.95(s)$ \\
$\underline{\mathbf{C}}^{1}-\mathrm{OH}$ & $151.7(s)$ & - & $151.9(s)$ & - \\
\hline
\end{tabular}

$(s)=$ Singlet; $\mathrm{Ar}=$ Aromatic.

also an upfield shift from 62.68 p.p.m. -64.40 p.p.m. to 58.33 p.p.m. -58.85 p.p.m. and from 56.01 p.p.m. -56.04 p.p.m. to 55.90 p.p.m.55.95 p.p.m. with respect to the free ligand in the signals for the methylene and methoxy carbons, respectively, upon co-ordination to the metal centre as per reported by Mahamo et al. (2012) and Dilworth et al. (1994). In the free ligands, C-OH signals appear at 151.7 p.p.m.-151.9 p.p.m. (Şenol et al. 2011) and disappeared upon complexation where the phenolic moiety was deprotonated.

\section{Molar Conductance and Magnetic Moment}

The molar conductance values of the $\mathrm{Pd}(\mathrm{II})$ complexes was found to be $0 \Omega^{-1} \mathrm{~cm}^{2} \mathrm{~mol}^{-1}$ suggesting their non-electrolytic nature (BenSaber et al. 2005). The magnetic moment of the complexes revealed their diamagnetic nature where $\mu_{\text {eff }}=0$, consistent with the expected square planar geometry (Raman et al. 2007).

\section{Catalytic Activity}

The Pd(II) complexes namely OPd 1 and OPd3 were tested as catalysts in the Suzuki-Miyaura cross-coupling reaction of iodobenzene with phenylboronic acid in the presence of triethylamine $\left(\mathrm{Et}_{3} \mathrm{~N}\right)$ as base in $\mathrm{N}, \mathrm{N}$-dimethylacetamide (DMA) at $100^{\circ} \mathrm{C}$. $\mathrm{Et}_{3} \mathrm{~N}$ that is soluble in the reaction mixture was a good base for the reaction due to its capability to give high conversion, although in its presence trace quantities of palladium metal could occasionally be observed as a precipitate against the walls of the glass tubes.

In most of the cases, $\mathrm{Et}_{3} \mathrm{~N}$ was the base of choice to activate the boron species in order to increase its nucleophilicity and give a clean reaction. This is because the organoborons compounds are highly covalent in character (Matos \& Soderquist 1998). Solubility of the bases plays a great rule in Suzuki-Miyaura coupling reaction (Papp et al. 2006).

The reaction was monitored using GC-FID by percentage conversion of iodobenzene at every $3 \mathrm{~h}$ and sampling was done at 3, 6, 9, 12 and $24 \mathrm{~h}$. A control reaction without catalyst had been set up and there was no indication of iodobenzene conversion after $24 \mathrm{~h}$.

The results are summarized in the Figure 5. It is observed, with increasing time, the \% 


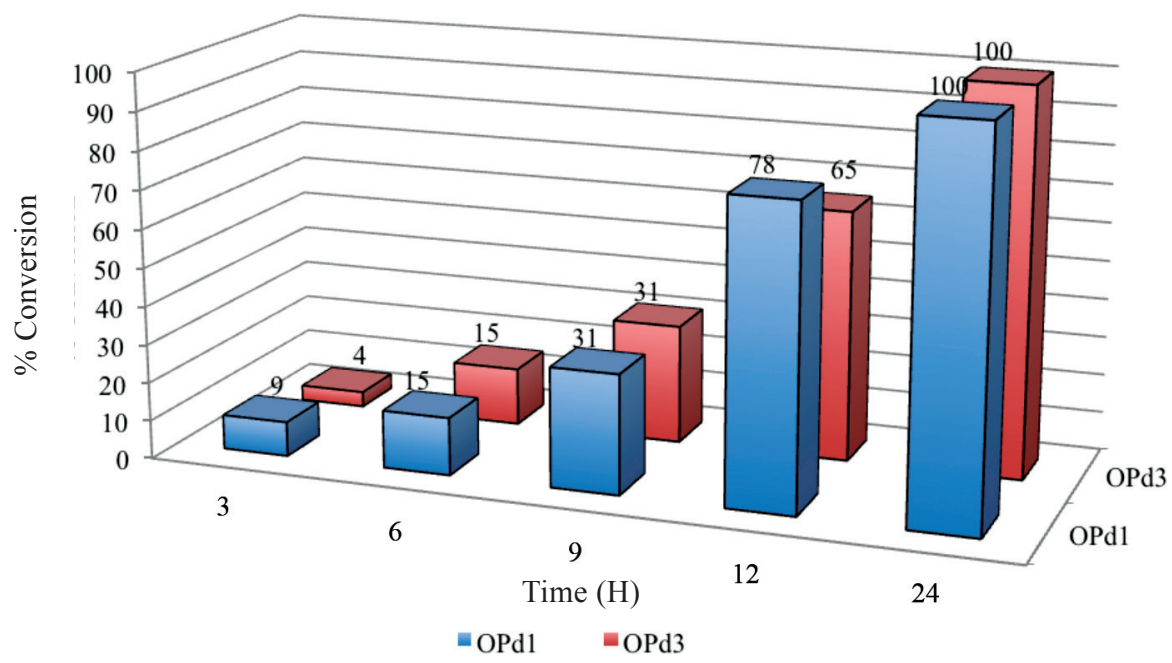

Figure 5. Percentage conversion of Iodobenzene using OPd1 and OPd3 as catalysts within $24 \mathrm{~h}$.

conversion of iodobenzene also increased. OPd1 showed its ability to convert iodobenzene faster than OPd3 in the early hours. At the end of the reaction, phenylboronic acid was found to couple smoothly with iodobenzene providing excellent yields up to $100 \%$ after $24 \mathrm{~h}$ for both catalysts.

\section{CONCLUSION}

Two ligands and their Pd(II) complexes were successfully synthesized as confirmed by the characterization via various physicospectral techniques. The Schiff base ligands co-ordinated through phenolic oxygen and azomethine nitrogen atoms as bidentate chelates as indicated by the spectral data. It was observed that both $\mathrm{Pd}(\mathrm{II})$ complexes, OPd1 and OPd3 displayed properties of good catalysts for the reaction, with up to $100 \%$ conversion of iodobenzene after $24 \mathrm{~h}$ of reaction time at $100^{\circ} \mathrm{C}$ in inert conditions.

\section{ACKNOWLEDGEMENTS}

Thanks are gratefully extended to Universiti Teknologi MARA and the Ministry of Education of Malaysia for scholarship and FRGS grants no. 600-RMI/FRGS 5/3 (51/2013) and 600RMI/FRGS 5/3 (52/2013).

Date of submission: September 2013

Date of acceptance: September 2014

\section{REFERENCES}

Ben-saber, SM, Maihub, AA, Hudere, SS \& Elajaily, MM 2005, 'Complexation behavior of Schiff base toward transition metal ions', Microchemical Journal, vol. 81, no. 2, pp. 191-194.

Bhunia, S, Sen, R \& Koner, S 2010, 'Anchoring of palladium(II) in chemically modified mesoporous silica: an efficient heterogeneous catalyst for Suzuki cross-coupling reaction', Inorganica Chimica Acta, vol. 363, no. 2, pp. 3993-3999.

Cozzi, PG 2004, 'Metal-Salen Schiff base complexes in catalysis: practical aspects', Chemical Society Reviews, vol. 33, no. 7, pp. 410-421.

Dhara, K, Sarkar K, Srimani D, Saha, SK, Chattopadhyaye P \& Bhaumik, A 2010, 'A new functionalized mesoporous matrix supported Pd(II)-Schiff base complex; an efficient catalyst 
for the Suzuki-Miyaura coupling reaction', Dalton Transactions, vol. 39, no. 28, pp. 63956402.

Dilworth, JR, Howe, SD, Hutson, AJ, Miller, JR, Silver, J, Thompson, RM, Harman, M \& Hursthouse, MB 1994, 'Complexes of functionalised phosphine ligands. Part 1. Complexes of $\mathrm{Fe}^{\mathrm{III}}, \mathrm{Co}^{\mathrm{III}}, \mathrm{Ni}^{\mathrm{II}}$ and $\mathrm{Re}^{\mathrm{V}}$ with tridentate Schiff bases having PNO, NNO and NNS donor sets. Crystal structures of $2-\left(\mathrm{Ph}_{2} \mathrm{PC}_{6} \mathrm{H}_{4} \mathrm{~N}=\mathrm{CH}\right) \mathrm{C}_{6} \mathrm{H}_{4} \mathrm{OH}$ and [ $\mathrm{Co}\{2-$ $\left.\left(\mathrm{Ph}_{2} \mathrm{PC}_{6} \mathrm{H}_{4} \mathrm{CH}=\mathrm{N}\right) \mathrm{C}_{6} \mathrm{H}_{4} \mathrm{O}_{2}\right]\left[\mathrm{PF}_{6}\right]$ ', Journal of The Chemical Society, Dalton Transactions, no. 24, pp. 3553-3562.

Gillis, EP \& Burke, MD 2009, 'Iterative crosscoupling with MIDA boronates: towards a general platform for small-molecule synthesis', Aldrichimica Acta, vol. 42, no. 1, pp. 17-27.

Gupta, KC \& Sutar, AK 2008, 'Catalytic activities of Schiff base transition metal complexes', Coordination Chemistry Reviews, vol. 252, no. 12-14, pp. 1420-1450.

Mahamo, T, Mogorosi, MM, Moss, JR, Mapolie, SF, Slootweg, JC, Lammertsma, K \& Smith, GS 2012, 'Neutral palladium(II) complexes with P,N Schiff-base ligands: Synthesis, characterization and application as Suzuki-Miyaura coupling catalysts', Journal of Organometallic Chemistry, vol. 703, pp. 34-42.

Matos, K \& Soderquist, JA 1998, 'Alkylboranes in the Suzuki-Miyaura coupling: stereochemical and mechanistic studies', Journal of Organic Chemistry, vol. 63, no.3, pp. 461-470.

McGlaken, GP \& Fairlamb, JS 2009, 'Palladiumcatalysed cross-coupling and related processes: some interesting observations that have been exploited in synthetic chemistry', European Journal of Organic Chemistry, vol. 2009, no. 24, pp. 4011-4029.

Miyaura, N \& Suzuki, A 1995, 'Palladium-catalyzed cross-coupling reactions of organoboron compounds', Chemical Reviews, vol. 95, no. 7, pp. 2457-2483.

Mohamed, GG, Zayed, MA \& Abdallah, SM 2010, 'Metal complexes of a novel Schiff base derived from sulphametrole and varelaldehyde. Synthesis, spectral, thermal characterization and biological activity', Journal of Molecular Structure, vol. 979, no. 1-3, pp. 62-71.
Mustafa, IM, Hapipah, MA, Abdulla, MA \& Ward, TR 2009, 'Synthesis, structural characterization, and anti-ulcerogenic activity of schiff base ligands derived from tryptamine and 5-chloro, 5-nitro, 3,5-ditertiarybutyl salicylaldehyde and their nickel(II), copper(II), and zinc(II) complexes', Polyhedron, vol. 28, no. 18, pp. 3993-3998.

Osman, AH 2006, 'Synthesis and characterization of cobalt(II) and nickel(II) complexes of some Schiff bases derived from 3-hydrazino-6methyl[1,2,4] triazin-5(4H)one', Transition Metal Chemistry, vol. 31, no. 1, pp. 35-41.

Ouf, AE, Ali, MS, Saad, EM \& Mostafa, SI 2010, 'pH-Metric and spectroscopic properties of new 4-hydroxysalicylidene-2-aminopyrimidine Schiff-base transition metal complexes', Journal of Molecular Structure, vol. 973, no. 1-3, pp. 69-75.

Papp, A, Tóth, D, Molnár, A 2006, 'SuzukiMiyaura coupling on heterogeneous palladium catalysts', Reaction Kinetics, Mechanisms and Catalysis, vol. 87, no. 2, pp. 335-342.

Paul, S \& Clark, JH 2003, 'A highly active and reusable heterogeneous catalyst for the Suzuki reaction: synthesis of biaryls and polyaryls', Green Chemistry, vol. 5, no. 5, pp. 635-638.

Raman, N, Sakthivel, A \& Rajasekaran, K 2007, 'Synthesis and spectral characterization of antifungal sensitive schiff base transition metal complexes', Mycobiology, vol. 35, no. 3, pp. 150-153.

Saheb, V \& Sheikhshoaie, I 2011, 'A new Schiff base compound N,N'-(2,2-dimetylpropane)bis(dihydroxylacetophenone): synthesis, experimental and theoretical studies on its crystal structure, FTIR, UV-visible, ${ }^{1} \mathrm{H}$ NMR and ${ }^{13} \mathrm{C}$ NMR spectra', Spectrochimica Acta Part A, vol. 81, no. 1, pp. 144-150.

Sallam, SA 2006, 'Binuclear copper(II), nickel(II) and cobalt(II) complexes with $\mathrm{N}_{2} \mathrm{O}_{2}$ chromophores of glycylglycine Schiff-bases of acetylacetone, benzoylacetone and thenoyltrifluoroacetone', Transition Metal Chemistry, vol. 31, no. 1, pp. 46-55.

Şenol, C, Hayvali, Z, Dal, H \& Hökelek, T 2011, 'Syntheses, characterizations and structures of NO donor Schiff base ligands and nickel(II) and copper(II) complexes', Journal of Molecular Structure, vol. 997, no. 1-3, pp. 53-59. 
Singh, BK, Rajour, HK \& Prakash, A 2012, 'Synthesis, characterization and biological activity of transition metal complexes with Schiff bases derived from 2-nitrobenzaldehyde with glycine and methionine', Spectrochimica Acta Part A, vol. 94, pp. 143-151.

Tamizh, MM, \& Karvembu, R 2012, 'Synthesis of triethylphosphite complexes of nickel(II) and palladium(II) with tridentate Schiff base ligand for catalytic application in carbon-carbon coupling reactions', Inorganic Chemistry Communications, vol. 25, pp. 30-34.
Torborg, C \& Beller, M 2009, 'Recent applications of palladium-catalyzed coupling reactions in the pharmaceutical, agrochemical, and fine chemical industries', Advanced Synthesis Catalysis, vol. 351, no. 18, pp. 3027-3043.

Zolezzi, S, Decinti, A \& Spodine, E 1999, 'Syntheses and characterization of copper(II) complexes with Schiff-base ligands derived from ethylenediamine, diphenylethylenediamine and nitro, bromo and methoxy salicylaldehyde', Polyhedron, vol. 18, no. 6, pp.897-904. 